\title{
A Digital Circular Economy for Smart Cities
}

\author{
Kannikar Khaw-ngern ${ }^{1}$, Lampong Klomkul ${ }^{2}$, Prateep Peuchthonglang ${ }^{3}$, Chainarong Khaw-ngern ${ }^{4}$ \\ ${ }^{1}$ Faculty of Buddhism, Mahachulalongkornrajavidyalaya University, \\ ${ }^{2}$ Faculty of Education, Mahachulalongkornrajavidyalaya University, \\ ${ }^{3}$ Faculty of Business Administration and Liberal Arts, Rajamangala University of Technology Lanna, \\ ${ }^{4}$ Faculty of Humanities, Mahachulalongkornrajavidyalaya University \\ ${ }^{1}$ kannikar.khaw@gmail.com, ${ }^{2}$ research.mcu@gmail.com, ${ }^{3}$ Khun_Jedrin@ hotmail.com, ${ }^{4}$ chainarong.kha@mcu.ac.th
}

\begin{abstract}
Due to the growing global population, the middle class is estimated to reach 5 billion by 2030, and all countries aim to increase their prosperity. This has caused enormous stress on our environment and our resources, which are reducing and becoming more difficult to extract. What worsens the situation is that manufacturers and consumers have tried to produce and consume as cheaply as possible. That has created a linear economy where objects are briefly used and then discarded as waste. The purpose of this article is to review the concept of smart city and how it can be implemented to promote circular economy, to study the difference between of digital city, intelligent city, smart city, and eco-city, to examine the role of digital technology in solving complexity in circular economy and how its functionalities in circular business models. Three case studies: Alpha, Philips CityTouch, and ZenRobotics have been reviewed. The result showed that digital technology can be mainly used for data collection, data exchange, data storage, and data analysis. Data analysis functionalities can be identified as monitoring and reporting product location, product condition and product availability; notifying predictive and preventive maintenance; identifying remanufacturing opportunities; optimizing product's energy consumption; enabling recycling, remanufacturing, product design and pricing; creating the intelligent product and virtual communication. Digital technologies are effective enablers for moving towards a circular economy which can deliver benefits for economy and environment such as increasing efficiency of raw material, reducing resource extraction, stimulating innovative designs, promoting production and remanufacturing, ensuring better distribution, consumption, reuse, and repair, as well as reducing waste.
\end{abstract}

Keywords

Digital Technology, Circular Economy, Smart City, Circular City, Digital Circular

Article Received: 10 August 2020, Revised: 25 October 2020, Accepted: 18 November 2020

\section{Introduction}

Cities now realize that becoming a 'smart city' is not an end state, but rather a process, which enables an efficient and ongoing evolution of technical solutions across city services. The key is being able to balance strategic vision with a practical plan that delivers near-term results while bolstering public support for more comprehensive investments in modernisation. Fundamentally, transformation is about resourcefulness. That is, using innovative technologies that enable communities to do more while using less [1]. In some cities, this may mean investing in smart water systems that help accurately track usage and minimise waste. Elsewhere, the priority may be accelerating adoption of carbon-free transportation. The trend in recent years of creating roles such as chief innovation, technology, or sustainability officers who assemble their own team is a major step in the right direction.

Digital connections all over the world are becoming broader and faster which provides a platform for businesses and industries to promote productivity and innovation. McKinsey Global Institute finds that the four commercial domains; mobility, healthcare, manufacturing, and retail, could increase global GDP by $\$ 1.2$ trillion to $\$ 2$ trillion by 2030 , and the countries that are most connected today are capturing much of the value. Importantly, two billion new users are set to come online worldwide which generates another $\$ 1.5$ trillion to $\$ 2$ trillion in GDP impact, mostly in the developing world [2]. Therefore, smart technologies basically are tools for becoming more efficient in the economy. Now technology is being brought more directly into the lives of residents. Smartphones are now used widely in the city, sending instant information about transit, traffic, health services, safety alerts, and community news into millions of hands. That means technology and data have been used purposefully to make better decisions and deliver a better quality of life. It is found that cities can use smart technologies to improve some key quality-of-life indicators by 10 to $30 \%$ [3]

A circular city is the city that adopts the principles of a circular economy across all its functions and establishes an urban system that is regenerative and restorative by design. These cities focus on eliminating waste, keeping assets at their highest utility at all times, and are enabled by digital technology. A circular city tries to promote prosperity and economic resilience in the city and its people, while separating this value creation from the consumption of finite resources [4].

\section{Smart Cities}

A smart city is a city that uses different electronic devices to collect data, and the date is processed and used to manage resources, assets, and services efficiently; in return, that data is used to address problems in the city and improve the operations across the city [5]. Smart city policies are not fixed, they can change according to the priorities of the city. For example, Korea offers an interesting example of how smart city policies have changed over time. Smart city in Korea is viewed as an engine of future growth, and also needs to be a place for innovative job creation rather than focusing on solving urban problems. That's why the smart 
city concept in Korea expanded to meet the perceived global standards of smart cities (Figure 1) [6].

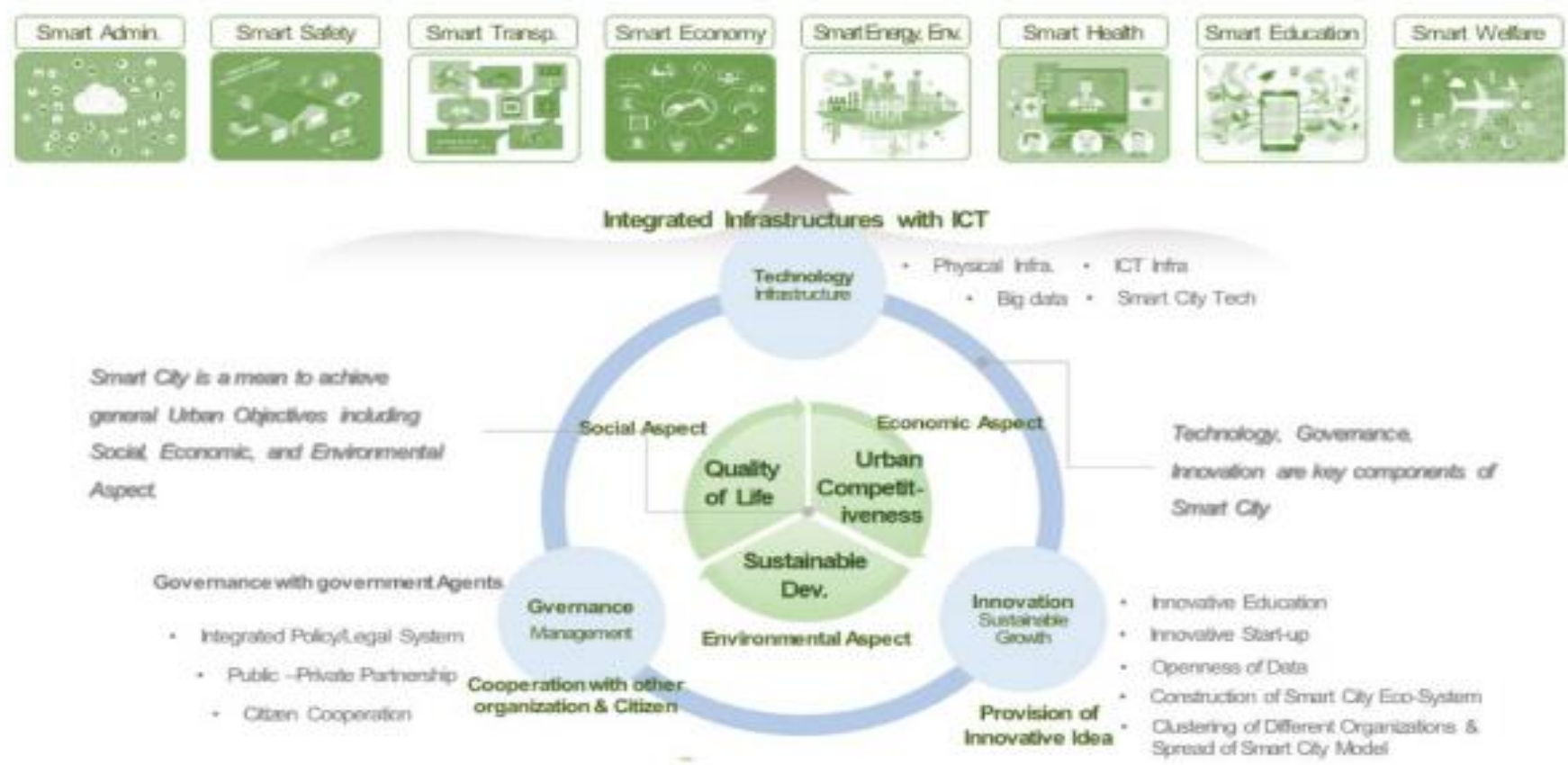

Figure 1. The renewed smart city concept in Korea [7]

There has not been unanimous agreement on what a smart city is and how it should be designed. However, smart cities mostly involve using digital innovation to manage the urban service efficiently as well as promote competitiveness and sustainability of a community. While digital innovation is a key element of the smart city concept, it is questioned whether investment in smart technologies and digital innovations ultimately contribute to improve the well-being of citizens. According to OECD, smart cities are defined as "initiatives or approaches that effectively utilise digitalisation to promote citizen well-being and deliver more efficient, sustainable and inclusive urban services and environments as part of a collaboration from multistakeholders" [8]. This definition focuses on four main issues: [9]

1. the need to document better the contribution of smart cities' to improving the life of people while continuing to deliver solutions to some of the most common urban challenges in a sectoral or multisectoral fashion;

2. the importance of stakeholder engagement in local governance and collaborative partnerships to boost civic engagement and leverage the role of the private sector in decision-making at the local level (citizen participation and feedback; co-creation and co-production models; citizencentered services and engagement platforms);

3 . the value of experimentation with public access to open data and collaboration within/between cities; private-publicpeople; national-regional-local scale; and

4. the need for an integrated and holistic approach to address urban challenges through digital innovation in a city's governance, planning, and infrastructure investment.

The concept of the smart city has been accepted and used in many countries as a vehicle for urban sustainability. The smart city process is about gathering data to monitor and optimize resource use through technology, and it has been a fundamental concept of the circular economy principles
[10]. In India, Ministry of Housing and Urban Affairs responsible for 100 cities under the program 'Smart Cities Mission' explained that a smart city provides for the aspirations and needs of the citizens with the aim of urban planners to develop the entire urban eco-system covering comprehensive development in four domains including institutional, physical, social and economic infra- structure. Due to its investment in long-term infrastructure to improve citizens' quality of life through the smart city mission, it could incorporate circular economy principles into the design of the infrastructure to provide water, sanitation, and waste services at scale as well as create effective urban nutrient and material cycles for the citizens [11]. Also, the better systemic planning of city spaces which is integrated with circular mobility solutions can increase air quality, lower congestion, and reduce urban sprawl. Flexible use of buildings and urban spaces which is enabled by digital applications, can increase utilization rates, getting more value out of the same assets. Higher efficiency and lower overall building and infrastructure costs could help meet the housing needs of the urban poor without compromising safety and quality.

According to the Ellen MacArthur Foundation report, three focus areas of the Indian economy and society include cities and construction, food and agriculture, and mobility and vehicle manufacturing [12]. The assumption that the Indian businesses should lead the way in the transition phase, with policymakers simultaneously setting the direction and creating the right enabling conditions could be discussed further. The transformation from a linear to a circular economy would require restructuring of production and consumption to promote environmental, social and economic sustainability [13]. 


\section{Digital Circular Economy}

A circular economy is one that aims to eliminate the concept of waste, emphasizing principles like durability, renewability, reuse, repair, and reduce material use. The concept seeks to bridge both environmental and economic concerns, according to Accenture, transitioning to a circular economy could unlock $\$ 4.5$ trillion of economic value, while also making businesses and communities more resilient [14].

Digital technology is incorporated into the cities according to the degree and nature of the technology capacity of the city from Digital Cities to Intelligent Cities to Smart Cities. Digital Cities integrate digital technology into the main infrastructure systems of the cities, while Intelligent Cities use the Digital City infrastructure to build intelligent buildings, transportation systems, schools, enterprises, public spaces, and public services, and integrate these into intelligent urban systems. Smart Cities install intelligent urban systems to promote socio-economic and ecological development, and to improve quality of life as well as address the origins of social instability in cities.

A Digital City is clearly based on the integration of digital technology into the city infrastructure system. However Intelligent Cities and Smart Cities incorporate more technology application including innovation, learning, knowledge creation and problem solving. Smart cities are different from Intelligent Cities because they emphasize on social and ecological aspects through people and environment dimensions. And Eco-Cities emphasize balanced co-existence of nature-made and human-made environments. Table 1 illustrates the major differences between the four models of cities.

Table 1. Comparing Digital City, Intelligent City, Smart City and Eco-City Models

\begin{tabular}{|l|l|l|l|}
\hline \multicolumn{1}{|c|}{ Digital City } & \multicolumn{1}{|c|}{ Intelligent City } & \multicolumn{1}{c|}{ Smart City } & \multicolumn{1}{c|}{ Eco-city } \\
\hline $\begin{array}{l}\text { Informatics } \\
\text { (communication) }\end{array}$ & $\begin{array}{l}\text { Intelligent systems } \\
\text { (functionality) }\end{array}$ & $\begin{array}{l}\text { Social and human } \\
\text { concerns (quality of life) }\end{array}$ & $\begin{array}{l}\text { Natural eco- } \\
\text { systems }\end{array}$ \\
\hline $\begin{array}{l}\text { City portals for } \\
\text { online information } \\
\text { services }\end{array}$ & $\begin{array}{l}\text { Online web-based e-learning } \\
\text { systems integrated and } \\
\text { interoperable with other city } \\
\text { platforms }\end{array}$ & $\begin{array}{l}\text { Ecological systems } \\
\text { (sustainability) }\end{array}$ & $\begin{array}{l}\text { Economic } \\
\text { development } \\
\text { while protecting } \\
\text { the environment }\end{array}$ \\
\hline & & $\begin{array}{l}\text { E-Learning platform and } \\
\text { knowledge management }\end{array}$ & \\
\hline & & $\begin{array}{l}\text { Advanced visualization } \\
\text { and simulation tools }\end{array}$ & \\
\hline & & $\begin{array}{l}\text { Benchmarking } \\
\text { requirements }\end{array}$ & \\
\hline & & & \\
\hline
\end{tabular}

As digitalisation is designed to solve complicated problems, gearing the use of data and digitally-enabled solutions to address the sustainability crisis offers many possibilities. Digitalisation can be incorporated into urban management system to boost the transformation towards a more sustainable circular economy. It can help to close material loops by reporting the availability, location, and condition of products. It helps businesses and industries manage their product value change more efficiently by reducing waste, extending product's life, and minimizing the transaction costs. Thus, it helps promote circular economy by closing the material loops, slowing the material loop, and narrowing the loop with increased resource efficiency.

Besides being used for tackling complexity in industrial processes and optimising manufacturing processes as well as promoting material efficiency in manufacturing firms, digital technology in term of 'smart technology' is also used in construction domain to promote efficiency and costeffectiveness in construction. Some examples include responsive heating, ventilation, and air conditioning (HVAC) systems, as well as smart meters that can provide greater transparency on energy consumption and cost. Other solutions are retrofit in existing buildings such as improving insulation and incorporating smart meters are estimated to reduce energy consumption by $20-30 \%$. Other more technologies that can be integrated in building to promote energy sustainability such as solar PV (photovoltaic) can help in the transition towards buildings as producers of energy rather than mere consumers. Green roofs, the same direction of technology, are also used to filter and capture rainwater. Recirculation of water within homes is another way to reduce a home's resource consumption. Figure 2 below illustrates some of the ways technology can unlock the circular potential in the built environment. 


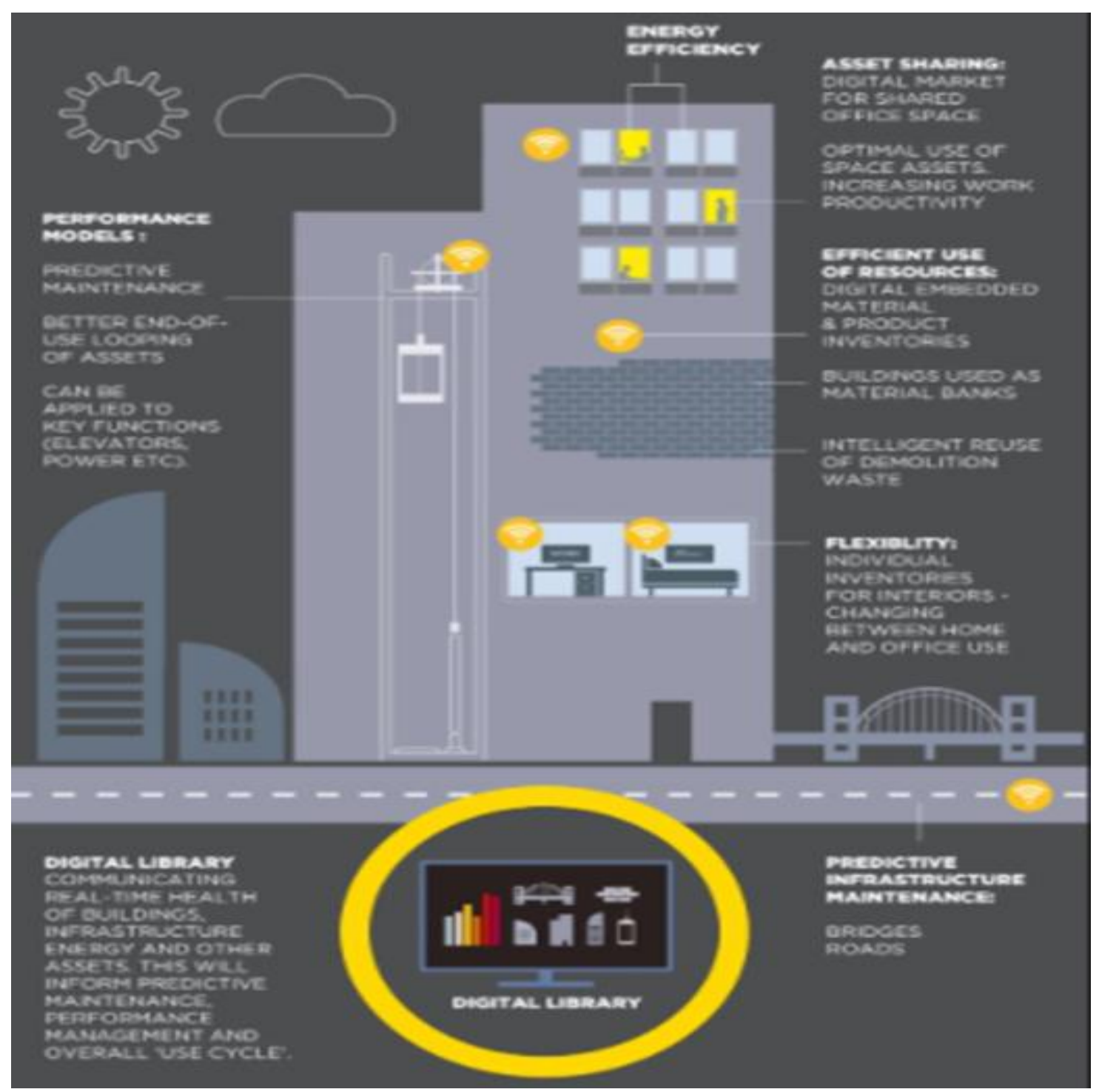

Figure 2. Connectivity for Buildings [15]

However, many challenges need to be solved, in order to gain the desired benefits and achieve digital technologyaided circular business models implementation. City planning should involve the issues of social inclusion, economic development and environmental protection, deploy public policies in pursuit of sustainability, and leverage digital technology in formulating and implementing such plans. City planning cannot be effective without learning from other cities, e.g., through the benchlearning, defining measurable goals and indicators, and deploying monitoring mechanisms to assess to what extent the goals are being met.

In the decades ahead, our cities and communities are expected to make a great deal of move towards circular economy as their infrastructures come under continual pressure from expanding populations. According to the United Nations statistic, it predicts that two-thirds of the world's people will live in urban areas by 2050 and that requires serious attention. Cities have an opportunity to improve quality of life by working on major local issues such as water and air quality, resource scarcity, traffic congestion and road safety as well as digital inclusion. Cities are also stepping up as key leaders in achieving environmental sustainability which is the priority of climate change action. If they are to achieve all of this, cities and communities must transform themselves into far more intelligent and agile organisations that can react and be flexible to the needs of citizens and businesses as well as respond to global demands and opportunities. As technology matures and new innovations emerge, cities and communities are empowered with even better solutions to become more efficient, sustainable and resilient. In short, if they are to be judged as successful, smart communities must ensure they deliver a social, economic and environmental benefit, providing a three-dimensional return on investment (ROI)

The digital/ICT industry has a significant environmental footprint. Data centers, digital devices and digital infrastructures require (often critical) levels of energy and materials. ICT accounts for 5 to $9 \%$ of the total electricity demand (associated with GHG emissions) with a potential increase to $20 \%$ by 2030 , as the demand for data centers, cloud computing and other energy-intensive technologies (e.g. blockchain) increases [16]. When considering the amount of energy digitalisation requires, these developments can also bring with them a transition in our energy system (e.g. increasing energy efficiency and share of renewables). Simultaneously, resource use and waste are a problem. The world produces annually 5 million tonnes (MT) of e-waste 
in 2019, and the amount is increasing due to rapid technical development [17]. This is a missed economic opportunity, as enormous amounts of valuable, critical materials are thrown away. Landfilling and informal recycling of e-waste also produce unwanted health and pollution impacts.

Smart City initiatives need to overcome or provide solutions to different types of challenges as follows: [18]

1) Economic Challenges - Examples include improving local competitiveness against regional and international markets, diversifying economic activities, obtaining funding for Smart City initiatives, overcoming spatial inequalities in productivity and income, reducing pressures to the resource base due to growth of urban populations, reducing capital and operational expenditures, facing budget cuts affecting local governments, and controlling efforts driven by wild capitalism.

2) Social Challenges - Examples include ensuring equity and fairness, reinforcement of social and territorial cohesion, ensuring social inclusion, addressing political and ethnic tensions, increasing burden on adult social care, providing services for different communities in the city, and leveraging human capital.

3) Environmental Challenges - Examples include protecting natural resources and green areas, reducing emissions generated by transport systems, reducing energy consumption or using renewable energy, addressing environmental degradation caused by urbanization, following green practices, reducing dependency on gas and oil and air pollution, as well as addressing the scarcity of natural resources.

4) Technical Challenges - Examples include deployment of integrated city infrastructure and service platforms, solving machine-to-machine communication, ensuring system and data security, managing spectrum utilization, defining and adopting interoperability standards, providing analytical methods needed to integrate qualitative and quantitative data from various sources, making optimal use of interconnected information for improving efficiency of city operations, optimizing the use of limited resources, providing the appropriate technology when needed, ensuring a proper solution or a good practice to the local conditions, and producing and delivering scalable solutions.

5) Service Delivery Challenges - Examples include increased demand for energy, water and sanitation; increased waste generation and shortfalls in municipal budgets to collect and proper dispose of waste; increased requirement on housing and transport systems; improving public safety by reducing crime and emergency response time; minimizing traffic congestions; ensuring the construction of comfortable city facilities and buildings; improving quality of services by providing innovative services and streamlining and tailoring services to address citizens' needs; ensuring the right levels of security and resilience across delivery models; updating new releases of public services without major disruptions against ongoing service delivery; ensuring $24 / 7$ service availability and customers' satisfaction by maintaining data and information up to date.

6) Financial Challenges - Examples include ensuring availability of financial resources; addressing possible lack of capacity for attracting investors; ensuring the construction of cost-effective buildings and facilities; reducing operational costs; and delivering long-term sustainable solutions.

7) Governance Challenges - Examples include engaging private sector in testing solutions, adopting decisions and proposals made by citizens; defining the proper role for private sector actor interventions - defining how, where, and when they should be engaged; attracting talent; enabling distributed implementation and execution by different stakeholders supported by central coordination; and establishing a governance committee with broad representation of government levels and societal sectors.

8) Institutional Challenges - Examples include ensuring departmental coordination and alignment, overcoming bureaucracy in government agencies, attracting qualified IT professionals and relevant IT players, and having qualified human resources for service delivery.

The major economic benefit that the circular economy provides at a macroeconomic level is that it is able to decouple economic growth from resource consumption. Many social aspects would be influenced by the adoption of a circular economy, including an increase in employment opportunities (i.e., in Europe alone, the transition towards a circular economy is estimated to generate 580,000 jobs [19]. Moreover, more resilient cities would be generated, providing a healthier space for citizens to live in. The circular economy has the potential to reduce the input of resources (e.g. energy) and output of materials (e.g. CO2 emissions). There, however, are still challenges need to be addressed. The first challenge is initial investments such as the adoption of new technologies. Second, how cities promote understanding and develop correct measurement of circularity performance. Third, the benefit of the adoption of new practices and the return on investment are still unclear. Additionally, thinking systemically and leading by example is necessary rather than thinking of individual impacts as an isolated and innocuous impact in the world. It would be beneficial if each of us thinks about our impacts as part of a bigger system.

\section{Digital Circular Economy: Case Study}

Circular Economy (CE) is an economic system aiming to close material and energy loops in production and consumption systems. Digital technologies (DT), such as Internet of Things, Big Data Analytics and Artificial Intelligence can effectively support the Circular Economy implementation [20]. Following are some case studies of circular economy integrated the use of digital technology. Alpha Case: Alpha is a household appliance retailer in Northern Europe. Instead of selling the electric appliance such as washing machines and dishwashers to households, it offers service contracts/subscriptions which customers can access and use the appliance on the monthly-payment or pay-per-use basis [21]. With the use of IoT kit, the standalone appliances are transformed into smart and connected products [22]. The IoT technology enables the tracking and monitoring of product activity during the usage phase. The information collected by IoT is also used for providing better technical support in the field [23]. Besides, IoT enhances renovation and end-of-life activities because the company knows the appliance position in real time, and they can organize better collection activities when each 
subscription ends. Moreover, information regarding product status and condition may be useful to enhance other closedloop activities, such as refurbishment, remanufacturing, and recycling.

Philips CityTouch case: This business model is the cooperation between city authorities and Phillips. The lightings are remotely managed on the cloud-based platform through the IoT network created by intelligent lightings. These intelligent lightings allow Philips to offer remanufactured products and not to lose the value embedded in the used city lightings. The company, city authorities and the intelligent lightings communicate through lighting management software. Philips can maintain the system, city authorities can control the system and lightings are acting as an intelligent object that can communicate with them. Thus, with this control mechanism, the stakeholders can save energy and material by optimizing energy consumption of the lightings and generate more revenue from the retrieved value of remanufactured re-source [24].

ZenRobotics case: This waste management solution uses AI algorithms to enable the main activity of recycling: waste sorting and reprocessing of materials. In order to achieve a high rate of pure secondary materials, it is essential to start with accurate waste separation for the right recycling process. With user-friendly AI software, the waste robots can be trained and interface. Thus, this technology suits to different industries and to different waste types. It is also a suitable solution for enterprises seeking to create partnerships with recycling firms using this kind of intelligent solution. With the use of AI, it is easier to use retrieved resources to offer recycled products and to create positive impact for the environment. ZenRobotics offers the least expensive and the most efficient solution to waste separating [25].

It can be seen that digital technology is mainly used for data collection, data exchange, data storage, and data analysis. Data analysis functionalities can be identified as monitoring and reporting product location, product condition and product availability; notifying predictive and preventive maintenance; identifying remanufacturing opportunities; optimizing product's energy consumption; enabling recycling, remanufacturing, product design and pricing; creating the intelligent product and virtual communication. Digital technologies are effective enablers for moving towards a circular economy which can deliver benefits for economy and environment such as increasing efficiency of raw material, reducing resource extraction, stimulating innovative designs, promoting production and remanufacturing, ensuring better distribution, consumption, reuse, and repair, as well as reducing waste (Figure 3) [26].

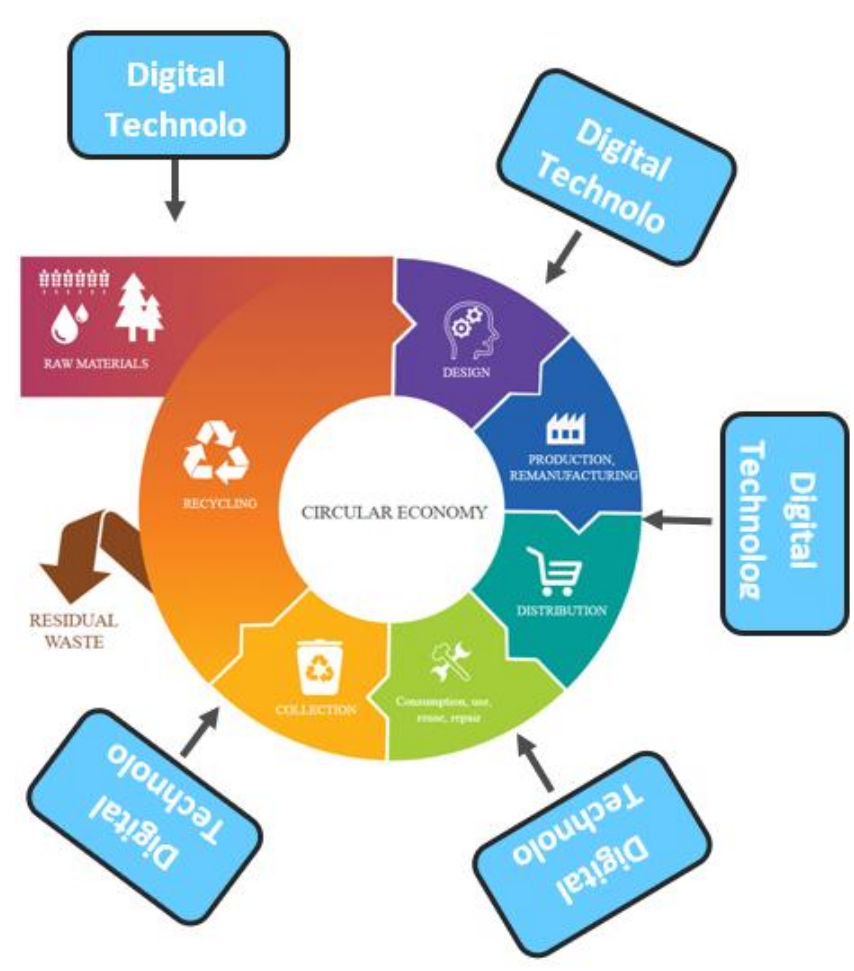

Figure 3. Digital Circular Economy (modified from Circular economy www.europarl.europa.eu) [27]

The United Nations SDGs call for action to end poverty, protect the planet and ensure that all people enjoy peace and prosperity.' The seventeen Global Goals came into effect in 2016 with the aim to guide the world towards a sustainable development path by 2030 . The circular economy, thus, has the potential to achieve many of these goals and sets out a clear framework for practices towards the goal. When it comes to approaching the goals, a systems perspective that recognises interconnections is crucial because all the goals aim to promote long term sustainable economic, social and environmental prosperity, aligning with the United Nation's Sustainable Development Agenda. The objectives include strengthening resilience to climate change, addressing environmental challenges like resource depletion and pollution, increasing competitiveness and innovation, contributing to industrial modernisation and security, and supporting social cohesion. Data and digital-enabled solutions such as digital platforms, smart devices, the Internet of Things and blockchain, and artificial intelligence are already contributing to the circular economy. They are used inter alia to promote natural resources efficiency, help in design, production and consumption, as well as ensure reuse, repair, remanufacturing, recycling and improve the overall waste management. It is important to understand that a $\mathrm{CE}$ and digital transitions must be co-managed and employed as the means to ensure long-term prosperity in accordance with the SDGs, the Paris Agreement and climate-neutrality goals.

\section{Conclusion}

Cities now recognise that becoming a 'smart city' is not an end state, but rather a process, which enables an efficient and ongoing evolution of technical solutions across city 
services. The key is being able to balance strategic vision with a practical plan that delivers near-term results while bolstering public support for more comprehensive investments in modernisation. Every city has different demands and challenges. Fundamentally, transformation is about resourcefulness. That is, using innovative technologies that enable communities to do more while using less. In some cities, this may mean investing in smart water systems that help accurately track usage and minimise waste. Elsewhere, the priority may be accelerating adoption of carbon-free transportation. The trend in recent years of creating roles such as chief innovation, technology, or sustainability officers who assemble their own team is a major step in the right direction.

Digital technology is incorporated into the cities according to the degree and nature of the technology capacity of the city from Digital Cities to Intelligent Cities to Smart Cities. Digital Cities integrate digital technology into the main infrastructure systems of the cities, while Intelligent Cities use the Digital City infrastructure to build intelligent buildings, transportation systems, schools, enterprises, and public services, as well as integrate these into intelligent urban systems. Smart Cities use intelligent urban systems to promote socio-economic and ecological development, and to improve quality of life as well as to identify the origins of social instability in cities.

Due to the socio-economic impact of the environmental crisis and of the ongoing climate changes, all stakeholders should work together towards a circular recovery and a more resilient future. A systemic shift to a circular economic model is required to achieving climate neutrality, fostering a thriving society, and keeping resource consumption within planetary boundaries. Circular economy is a transition from linear take-make-use-dispose to a close-loop of production and consumption. It needs collaboration from citizens, businesses and the research community to enable its function in an integrated way. It is a business model decoupling resource use from economic activity by maintaining the value and utility of products, components, materials and nutrients for as long as possible, in order to close material loops and reduce harmful resource use and waste generation. Through this circular transition, we can improve human wellbeing, reduce emissions, protect and enhance biodiversity, and promote social justice, in line with the Sustainable Development Goals.

Cities are center of innovation and socio-economic transformation and have potential to lead the transition to a circular economy. They are a place to foster a circular economy and lead the way towards a more sustainable, resilient future. The key is building in flexibility from the start with open platforms and partnering with an ecosystem of vendors who understand the importance of working together and ensuring their technologies talk to each other. Digital technology can be functioning for data collection, data exchange, data storage, and data analysis. With digital technology support, businesses and industries can monitor and update product location, product condition and product availability as well as optimize product's energy consumption, recycling, remanufacturing, and product design. Digital technologies are effective enablers for moving towards a circular economy which can deliver benefits for human, society, economy and environment in a sustainable way. According to the United Nations, circular cities will be a major engine for pursuing the Sustainable Development Goals.

\section{References}

[1] Itron. (2019) Smart cities: Where's the ROI? Retrieved 12 October 2020 from https://www.smart citiesworld.net/whitepapers/smart-citieswheres-the-roi

[2] MGI. (2020) Connected world: An evolution in connectivity beyond the $5 \mathrm{G}$ revolution. Discussion paper. McKinsey Global Institute.

[3] Woetzel, J. et al. (2020) Smart cities: Digital solutions for a more livable future.

[4] Sukhdev, A. et al (2017) Cities in the circular economy: The role of digital technology. EMF.

[5] Lai, Chun Sing; Jia, Youwei; Dong, Zhekang; Wang, Dongxiao; Tao, Yingshan; Lai, Qi Hong; Wong, Richard T. K.; Zobaa, Ahmed F.; Wu, Ruiheng; Lai, Loi Lei (17 August 2020). "A Review of Technical Standards for Smart Cities". Clean Technologies. 2 (3): 290-310. doi:10.3390/cleantechnol2030019

[6] Caird, P. S. \& Hallett, H.S. (2019) Towards evaluation design for smart city development. Journal of Urban Design, 24 (2): 188-209.

[7] https://www.oecd.org/cfe/cities/OECD_Po licy_Paper__ Smart Cities_and_Inclusive_Growth.pdf

[8] OECD. (2018) Housing Dynamics in Korea: Building Inclusive and Smart Cities. Paris: OECD Publishing.

[9] OECD. (2020) Smart Cities and Inclusive Growth. Paris: OECD Publishing.

[10] EMF. (2019) Artificial Intelligence and the Circular Economy: AI as a tool to accelerate the transition. Cowes: Ellen MacArthur Foundation.

[11] EMF. (2016). Circular Economy in India: Rethinking growth for long-term 
prosperity. Cowes: Ellen MacArthur Foundation.

[12] Ellen MacArthur Foundation, SUN and McKinsey Center for Business and Environment, Growth Within: a circular economy vision for a competitive Europe (2015)

[13] Chaturvedi, A., Gaurav, J. K., \& Gupta, P. (2017). The Many Circuits of a Circular Economy. Brighton: STEPS Centre.

[14] Richer, E. (2018) How the digital revolution is helping cities go circular. Retrieved 12 October 2020 from https://blogs.cisco.com/government/howthe-digital-revolution-is-helping-cities-gocircular

[15] Ellen MacArthur Foundation, Intelligent Assets: Unlocking the Circular Economy Potential (2016)

[16] Enerdata. (2018) Between 10 and 20\% of electricity consumption from ICT sector in 2030? Retrieved 12 October 2020 from https://www.enerdata.net/publica tions/executive-briefing/world-energyconsumption-from-digitalization.pdf

[17] Abhiyan, I. (2020) Reports and Indices: Global E-waste Monotor 2020. Retrieved 12 October 2020 from https://www.iasabhiyan.com/global-ewaste-monitor-2020/

[18] Estevez, E. et al. (2016) Smart Sustainable Cities - Reconnaissance Study. Retrieved 12 October 2020 from https://www.researchgate.net/publication/ 299388106_Smart_Sustainable_Cities__Reconnaissance_Study

[19] CEC. (2020) No city left behind the circular economy revolution. Circular Cities Week Report. Circular Economy Club.

[20] G. Bressanelli, F. Adrodegari, M. Perona, N. Saccani "Exploring how usage-focused business models enable circular economy through digital technologies Sustain, 10 (3) (2018)

[21] Porter, M.E.; Heppelmann, J.E. How Smart, Connected Product Are
Transforming Competition. Harv. Bus. Rev. 2014, 92, 64-89.

[22] Rymaszewska, A.; Helo, P.; Gunasekaran, A. IoT powered servitization of manufacturing-An exploratory case study. Int. J. Prod. Econ. 2017, 192, 92105.

[23] Ece Uçar, Marie-Anne Le Dain, Iragaël Joly: Digital Technologies in Circular Economy Transition: Evidence from Case Studies https://www.researchgate.net/publication/3 43495456_Digital_Technologies_in_Circu lar_Economy_Transition_Evidence_from_ Case_Studies

[24] https://ec.europa.eu/environment/waste/stu dies/cdw

/CDW_Task\%202_Case\%20studies_ZenR obotics.pdf

[25] https://www.europarl.europa.eu/news/en/h eadlines /economy/20151201STO05603/circulareconomy-definition-importance-andbenefits 